\title{
To detach or not to detach? The role of psychological detachment on the relationship between heavy work investment and well-being: A latent profile analysis
}

\author{
Maria Gaudiino $^{1}$ (D) $\cdot$ Giovanni Di Stefano ${ }^{2}$ (D) \\ Accepted: 1 June 2021 / Published online: 22 June 2021 \\ (C) The Author(s) 2021, corrected publication 2021
}

\begin{abstract}
This study focuses on two types of heavy work investment, namely workaholism and work engagement, and on psychological detachment from work. Both workaholism and work engagement refer to an intense work effort, yet with a different impact on work and personal life. Building on Stressor-Detachment Model (SDM), we examine how different levels of workaholism, work engagement, and psychological detachment influence different outcomes related to employees' well-being (i.e., perceived health, negative affectivity, positive affectivity). Data were collected from 342 employees via online survey and analyzed by mean of latent profile analysis. Five employee profiles were identified: High-Detachment and Engaged, Heavy Work Investors, MildDetachment and Disengaged, Mild-Detachment and Engaged, and Pure Workaholics. The profiles showed different patterns of the outcomes under investigation. Our findings also indicate that psychological detachment is an important factor that alleviates the detrimental effects of heavy work investment on employees' well-being and that work engagement can play an immediate protecting role for employees' well-being even in absence of significant levels of psychological detachment.
\end{abstract}

Keywords Well-being at work $\cdot$ Psychological detachment $\cdot$ Workaholism $\cdot$ Work engagement $\cdot$ Latent profile analysis

Past research has shown that heavy work investment (HWI) has a critical impact on employees' well-being (Snir \& Harpaz, 2012). In general, HWI refers to two different, yet interrelated work attitudes, namely workaholism and work engagement (Di Stefano \& Gaudiino, 2019; Snir \& Harpaz, 2012). Workaholism refers to an intense need for work (Porter, 1996; Scott et al., 1997), implying an internal drive that continuously pushes workaholics towards job-related activities (Ng et al., 2007; Spence \& Robbins, 1992), without the necessary periods of rest (Taris \& Verhoeven, 2005). Conversely, work engagement refers to a "positive, fulfilling, work-related state of mind that is characterized by vigor, dedication, and absorption" (Schaufeli et al., 2002, p. 74).

Interestingly, although these two work attitudes show some similarities (i.e., workaholics and engaged employees may similarly work hard), they show different associations with

Giovanni Di Stefano

giovanni.distefano@unipa.it

1 Work and Organisation Studies, KU Leuven, Leuven, Belgium

2 Department of Psychology, Educational Science and Human Movement, University of Palermo, Palermo, Italy other work attitudes and several indicators of well-being (Taris et al., 2010). While work engagement is mostly associated with positive outcomes, workaholism is mostly associated with negative outcomes (e.g., Babic et al., 2019; Taris et al., 2015; van Beek, Taris, Schaufeli, \& Brenninkmeijer, 2014).

Previous studies have investigated workaholism and work engagement attempting to understand the distinctive characteristics of the two constructs, and their relationship with employee well-being outcomes (e.g., Gorgievski et al., 2010; Taris et al., 2010). Despite the fact that workaholism and work engagement are considered the "bad" and "good" type of HWI respectively, some specific aspects of their distinction are still unclear (Di Stefano \& Gaudiino, 2019; Shimazu \& Schaufeli, 2009; Taris et al., 2010). First, both workaholic and engaged individuals show intense effort in work (Schaufeli \& Salanova, 2011; Scott et al., 1997) and tend to exceed what is required by organizational or task demands (Porter, 1996; van Wijhe et al., 2011). Second, both types of workers seem to have difficulties to detach from the mental and physical job context (del Líbano et al., 2012; Schaufeli et al., 2008). Consequently, heavy work investors are more likely than non-heavy work investors to be exposed to psychological strain derived from work-related thoughts and worries, also during nonwork hours. Third, the workaholism-work 
engagement comparison gains even more complexity from a cross-national perspective. While previous studies have shown that in a cross-cultural context, the relationship between the two types of HWI and employee outcomes differ, research has failed to provide a systematic explanation for these results (Di Stefano \& Gaudiino, 2019; Hu et al., 2014; Schaufeli et al., 2019).

Prior findings on the overlapping features of workaholism and work suggest that more research is necessary (Gorgievski et al., 2010; Schaufeli et al., 2006b; Schaufeli et al., 2008) to fully understand the differences between these two concepts and achieve a more satisfying level of theoretical and empirical exploration. Since workaholism and work engagement affect employees' subjective well-being, it is also important for organizations to understand how to detect and distinguish the two types of heavy work investors; foster work engagement and sustain its positive features; prevent workaholic tendencies and protect employees from the potential negative consequences of going the extra mile.

In the current study, we advance that a factor that fosters employee well-being, namely psychological detachment from work, plays a role in alleviating the detrimental impact that can result from the high workload of heavy work investors on their well-being outcomes. Psychological detachment from work during off-job hours is a recovery experience involving a mental "switch off" from work (Sonnentag \& Fritz, 2007, 2015). Specifically, psychological detachment from work occurs not simply when employees are outside of their workplace and working hours, but when they are also able to disengage from work-related activities, thoughts, problems, and opportunities (Sonnentag \& Bayer, 2005; Sonnentag \& Kruel, 2006). Investigating such an ability in relation to HWI phenomenon can shed light on a resource people possess against the burden brought about by workload.

Thus, we address a double objective. First, by drawing on Stressor-Detachment Model (SDM; Sonnentag \& Fritz, 2015), we posit that psychological detachment has an important role in alleviating the potential negative impact of HWI and the consequent impact on well-being outcomes. From this perspective, the capacity to detach from work is seen as a condition under which the detrimental aspects of workaholism are counterbalanced and the benefits of work engagement are fostered. Second, we elaborate on the contribution of psychological detachment to clarify the distinction between the two types of HWI. Specifically, using Latent Profile Analysis (LPA), we observe different levels of workaholism and work engagement in their combination with psychological detachment and we examine how such combinations are associated with different patterns of individual wellbeing outcomes (i.e., perceived health, positive affectivity, negative affectivity). Thus, LPA allows to unravel the presence of peculiar patterns involving psychological detachment and either workaholism or work engagement, that in turn would suggest potential managerial implications and avenues for future research on the distinction of the two types of HWI. To the best of our knowledge, to date there is no research that investigates workaholism, work engagement, and psychological detachment together by mean of LPA strategy.

\section{Workaholism Vs. Work Engagement: Known Similarities and Differences}

The existence of some similarities between workaholics' and engaged employees' approach to work complicates their distinction at either a theoretical or a practical level, despite the past research efforts to shed light on the nature of the features underlying heavy work behaviors (del Líbano, 2011; Di Stefano \& Gaudiino, 2019; Schaufeli et al., 2008).

According to Schaufeli et al.'s (2009) widespread model, workaholism consists of two dimensions, working excessively and working compulsively. The former refers to the behavioral component of hard working (i.e., tendency to work long hours), while the latter refers to the underlying compulsive push to work and the typical sense of guilt of a workaholic who is not working. Interestingly, the use of these two dimensions of workaholism has revealed a moderate positive correlation between working excessively-not working compulsively-and work engagement (Schaufeli et al., 2009). As reported in Taris et al. (2010), previous findings have confirmed that workaholism and work engagement are positively associated with spending more hours at work. This gives support to the idea that compulsive tendencies have a key role in separating workaholism from work engagement, whereas excessive work is seen as the manifest dimension that workaholic and engaged employees share (Gorgievski et al., 2010; Hakanen et al., 2012; Schaufeli et al., 2006a).

Previous studies showed that workaholics mainly feel negative emotions and frustration due to their exhausting and compulsive way to work (e.g., Clark et al., 2014; van Wijhe et al., 2011). Workaholic employees generally report poorer health status, such as distress, anxiety, physical aches or work-life conflict, compared to nonworkaholic employees (e.g., Andreassen, 2014; del Líbano, 2011; Di Stefano \& Gaudiino, 2018; Fassel, 1990).

Conversely, Schaufeli et al. (2002) define work engagement as a pleasant work-related mental state, involving relatively stable affects and cognitions, that consists of three characteristics: vigor (i.e., energetic level that sustains strong effort at workplace), dedication (i.e., feelings and thoughts that make employees identified, proud, involved, and enthusiastic with their work), and absorption (i.e., the experience of deep concentration in work activity). Interestingly, several studies have found partial correlation between absorption and workaholism, thus lending empirical support to a similarity between the forms of HWI, specifically concerning behavioral dimension of overwork (e.g., del Líbano, 2011; Schaufeli et al., 2008). 
Nevertheless, being engaged at work tends to yield positive outcomes for individuals. For instance, engaged employees usually report having fun when doing their job and experiencing positive emotional states leading to increased personal resources (e.g., Binnewies \& Fetzer, 2010; Clark et al., 2014; van Wijhe et al., 2011). Similarly, engaged employees report better health status and higher life satisfaction, than nonengaged employees (e.g., Schaufeli et al., 2006b; Schaufeli et al., 2008; Shimazu \& Schaufeli, 2009).

\section{The Role of Psychological Detachment on the Relationship between Heavy Work Investment and Well-Being}

Working requires a psychological effort from employees every day. It has been widely acknowledged in occupational health research that it is important for employees to take mental breaks and have some respite from work activities in order to restore individual resources and maintain healthy life conditions (Bakker et al., 2013; Fritz \& Sonnentag, 2005, 2006).

Psychological detachment from work was introduced for the first time by Etzion, Eden, and Lapidot (1998) as "the individual's sense of being away from the work situation" (p. 579). Sonnentag and colleagues significantly contributed to broaden and deepen the research on psychological detachment from work during off-job time, among other recovery experiences (e.g., Sonnentag et al., 2010a; Sonnentag \& Fritz, 2007, 2015). Psychological detachment from work refers to the capacity of psychologically disengaging from work during off-job hours, and not thinking about work-related problems after having left the workplace (Sonnentag \& Bayer, 2005). Sonnentag et al. (2013) argue that the psychological detachment is not a passive type of avoidance coping. By contrast, psychological detachment allows people to recover from jobrelated efforts at the end of the workday, instead of ruminating about work that could negatively influence the nonwork sphere.

The ability to disconnect from work during off-job hours has been associated with positive employee outcomes including reduced psychological strain symptoms, higher life satisfaction, lower perceived workload and lower emotional dissonance (Sonnentag, 2012; Sonnentag et al., 2010b). A recent meta-analysis from Wendsche and Lohmann-Haislah (2017) reports that detachment from work is related to several indicators of employees' subjective well-being. Specifically, the authors found that psychological detachment is positively related to sleep and positive affect, and negatively related to burnout, fatigue, quantitative job demands, social conflicts and negative affect.

Prior research shows that employees with workaholic tendencies often fail to take the necessary mental breaks from their work tasks and seem to neglect leisure activities, thus not dedicating enough time to restoring their resources (Bakker et al., 2013; Shimazu et al., 2014). By contrast, engaged employees report a better work-life balance and more opportunities to restore their resources following work activities (Kühnel et al., 2009; Montgomery et al., 2003; ten Brummelhuis \& Bakker, 2012).

We argue that these findings can be explained by the Stressor-Detachment Model (SDM) (Sonnentag \& Fritz, 2015). According to SDM, psychological detachment from work can play a role between job stressors and employees' short- and long-term well-being.

Job stressors, such as negative emotions at work, high workload, concerns and pressure for strict deadlines drain individual resources, thus leading to psychological strain and poor well-being (Bakker \& Demerouti, 2017). In addition, the more people continue to think about work-related issues and be involved in work activities during their off-job hours, the less likely they will be able to restore their energies. The opportunity to regularly take a break from stressors or, in other words, the opportunity to detach from work during off-job hours, will alleviate the impact of job stressors on strain (Sonnentag \& Fritz, 2015).

Within the stressor-detachment framework, HWI can be considered a condition of having a high workload and little or no time to recover from work-related efforts (Snir \& Harpaz, 2012). However, the different HWI types have different consequences on people. Employees prone to workaholism - compared to nonworkaholics - are more likely to have negative emotions at work, to experience work-life imbalance and limited occasions to detach from work due to their compulsive approach to work (Schaufeli et al., 2009). Conversely, despite a high investment in their job, highly engaged employees are more likely to enjoy their work activities, keep their energy high at work, and maintain a good work-life balance (Taris et al., 2015).

Building on SDM, we argue that the opportunity to psychologically detach from work during nonwork time can help attenuate heavy work investors' strain resulting from high workload. More specifically, psychological detachment can help employees stop being involved in work-related thoughts and worries when it is not needed. This creates more opportunities to restore resources, which can be dedicated to the other nonwork activities (Sonnentag \& Bayer, 2005; Sonnentag et al., 2010a).

Prior empirical findings on the relationship between psychological detachment, HWI and employee outcomes are mixed. Two recent meta-analyses have investigated the relationship between psychological detachment and several employee-related variables (Bennett et al., 2018; Wendsche \& Lohmann-Haislah, 2017). Wendsche and LohmannHaislah (2017) included workaholism and work engagement as potential antecedent and outcome of detachment, respectively. In fact, in their meta-analysis, workaholism measures 
are included in the main category heavy work investment, among the person characteristics, while work engagement measures are considered within the main category of work motivation. The authors report a negative correlation between HWI and detachment and no significant correlation between detachment and work motivation (Wendsche \& LohmannHaislah, 2017). However, the categorization chosen to group the variables prevents to gauge any more precise result on the distinctive relations or combination among workaholism, work engagement, and psychological detachment. Conversely, Bennett et al. (2018) report a positive but weak correlation between psychological detachment and vigor, as one of the engagement dimensions.

Psychological detachment has also been investigated as a moderating variable of several employee antecedents and outcomes. For instance, Siltaloppi et al. (2009) argue that psychological detachment mitigates the negative impact of the lack of job control on employees' need for recovery. Sonnentag et al. (2013) found that employees, who experienced high levels of relational conflict at the workplace and had a high (low) capacity of psychological detachment from work reported higher (lower) well-being. However, this was not the case for those employees reporting high levels of task conflict, for which such an effect of psychological detachment did not emerge.

Consistent with the literature on the comparison between workaholism and work engagement (e.g., Snir \& Harpaz, 2012; Shimazu et al., 2015; Taris et al., 2010; Taris et al., 2015), the current contribution considers these concepts as two different types of HWI. In addition, the ability of psychological detachment is considered here as a meaningful characteristic of people, conducive to differences in the resulting employee well-being for heavy work investors. We expect therefore that employees showing workaholic tendencies and able to detach psychologically from work will experience better wellbeing than employees showing workaholic tendencies but not able to detach. Analogously, we expect that engaged employees able to detach psychologically from work will experience better well-being than engaged employees but not able to detach.

We investigate two indicators of employees' well-being, namely general health and perceived affectivity. It has been widely acknowledged that affectivity influences the appraisal of events and, as such, it is considered a well-being-related measure (Moyle, 1995; Spector et al., 2000). Furthermore, previous studies on workaholism and work engagement have shown that emotional states represent relevant factors in examining the differences between these two types of HWI (e.g., Schaufeli et al., 2006b; van Wijhe et al., 2011).

\section{A Person-Centered Perspective on Workaholism, Work Engagement and Psychological Detachment}

Due to the coexistence of differences and overlaps between workaholism and work engagement, more recently researchers have started to explore their relationships through a personcentered perspective (Gillet et al., 2018; Guidetti et al., 2020; Innanen et al., 2014; Mäkikangas et al., 2013). This perspective enables researchers to identify possible recurring patterns (i.e., combinations among dimensions or constructs) taking either an exploratory or a confirmatory approach.

Specifically, studies applying a person-centered perspective on HWI have investigated whether and how low or high levels of workaholism and work engagement can be "systematically" combined, so that particular employee profiles can be identified. In turn, the different profiles can be examined in their relationships with several variables, either possible antecedents or outcomes of the identified patterns. This approach allows scholars to contrast the profiles and highlight the differences between them. For instance, Gillet et al. (2018) based their hypotheses on van Beek et al.'s (2011) work and empirically examined employee profiles with different levels of workaholism and work engagement and overall identified four profiles (i.e., Engaged, Disengaged, EngagedWorkaholic, and Workaholic). In addition, the authors found that profiles with high level of workaholism, combined with either high or low level of work engagement, are associated with high negative employee outcomes. In a longitudinal study, Mäkikangas et al. (2013) found that workaholism and work engagement were not related to each other in a sample of managers, with workaholism tending to be more stable than work engagement over time.

To the best of our knowledge, to date only one study has taken into account the role of psychological detachment for testing profiles with different levels of workaholism and work engagement (Innanen et al., 2014). Specifically, Innanen et al. (2014) conducted a longitudinal study among highly educated employees and measured the four recovery experiences (i.e., psychological detachment, relaxation, master, control) as outcomes of the different patterns of burnout, engagement, and workaholism. The authors identified two profiles: Engaged employees (high engagement, low burnout, moderate workaholism) and Exhausted Workaholics (high exhaustion and workaholism). Engaged employees reported higher positive outcomes than Exhausted Workaholics, including more positive emotions, fewer negative emotions, and higher life satisfaction. In addition, Engaged employees reported higher psychological detachment from work during off-job hours and relaxation than Exhausted Workaholics (Innanen et al., 2014).

Our study aims to contribute to extant research by examining for the first time the patterns that emerge from the combination of workaholism, work engagement, and psychological detachment. Psychological detachment is included as a factor that can determine a variation in the outcomes of workaholic and engaged employees, thus allowing us to test whether a distinction can be made between the two work approaches. We will examine whether different profiles with different levels of psychological detachment, workaholism and work 
engagement emerge, and whether there are differences between these profiles and their relationship with well-being, positive and negative affectivity. In line with Spurk et al.'s (2020) illustrative example about the analysis of profiles, we follow an exploratory approach, and formulate our hypotheses without including any strict constraints.

We expect to identify different profiles with different levels of workaholism, work engagement, and psychological detachment. In addition, we expect that the strength of the relationships between the different profiles and well-being outcomes will differ as well. Since previous research has shown mixed results in particular about the relation between work engagement and psychological detachment (e.g., Kühnel et al., 2009; Shimazu et al., 2016; Shimazu et al., 2012; Siltaloppi et al., 2011; Sonnentag et al., 2010a), we assume that our analysis will reveal profiles with high engagement and high detachment, as well as profiles with high or low engagement and high or low detachment. Conversely, we do not expect to find any profile with high level of workaholism and high level of psychological detachment, due to the difficulty these employees have to take a mental break from work-related concerns (e.g., Bakker et al., 2013; Shimazu et al., 2014). Based on these considerations, we formulate the following exploratory hypotheses:

Hypothesis 1. There exist at least four different profiles: two profiles will both show high levels of work engagement, but high and low levels of psychological detachment, respectively; a third profile will show relatively low levels of all the three constructs; a fourth profile will be characterized by high levels of workaholism but low levels of work engagement and psychological detachment.

Hypothesis 2. Profiles with high levels of workaholism and low levels of work engagement will show more negative or less positive outcomes (more negative affectivity, less positive affectivity, worse general health) than profiles with low levels of workaholism and high levels of work engagement.

Hypothesis 3. Profiles with high levels of psychological detachment will show more positive or less negative outcomes (less negative affectivity, more positive affectivity, better general health) than profiles with low levels of psychological detachment.

\section{Method}

\section{Participants and Procedure}

Participants for this study were recruited online through the authors' personal and business contacts. Emails explaining the study and the requirements for inclusion were sent to 500
Italian employees working at different organizations. $68.4 \%$ of subjects agreed to participate and the final sample consisted of 342 employees ( $57 \%$ female) of various sectors (e.g., banking, health, food, industry, public administration) located in Southern Italy. Participants were not provided with any incentives to complete the survey.

A questionnaire containing the scales used for the study was administered via online survey. The subjects voluntarily filled in the questionnaire after they gave the informed consent on their participation to the study. The age in the sample ranged between 19 and 64 years, with average age of 42.88 years $(S D=12.57)$. $50.6 \%$ of participants worked in private sector and the average job tenure was 19.97 years $(S D=12.12)$. As for educational qualification, the largest part $(55.1 \%)$ had a high school diploma, $14.0 \%$ a secondary school certificate, $12.5 \%$ a bachelor's degree, $12.5 \%$ a master's degree, $5.3 \%$ a postgraduate qualification, and $0.8 \%$ a primary school certificate. Subjects' professional level was 5.3\% managers, $16.2 \%$ middle managers, $59.2 \%$ office workers, and $19.2 \%$ manual workers.

\section{Measures}

Workaholism Workaholism was assessed through the Italian version (Balducci et al., 2015) of 10-item Dutch Work Addiction Scale (DUWAS; Schaufeli et al., 2009), consisting of two 5-item subscales, Working Excessively (WE) and Working Compulsively (WC). Sample items are "I find myself doing two or three things at one time such as eating lunch and writing a memo, while taking on the telephone" (WE) and "I feel that there's something inside me that drives me to work hard" (WC). Subjects chose an alternative on a 4-point frequency scale, from 1 ([Almost] never) to 4 ([Almost] always). Cronbach's $\alpha$ in this study was .72.

Work Engagement In order to assess work engagement, we used the Italian version (Balducci et al., 2010) of Utrecht Work Engagement Scale (UWES; Schaufeli et al., 2006a), containing a 3-item scale for each dimension of work engagement (i.e., Vigor [VI], Dedication [DE], and Absorption [AB]). For instance: "At my job, I feel strong and vigorous" (VI), "My job inspires me" (DE), "I get carried away when I am working" (AB). Subjects answered on a 7-point frequency scale, from 0 (Never) to 6 (Always). Cronbach's $\alpha$ in this study was .92.

Psychological Detachment Psychological detachment was assessed through the 3-item subscale derived from Zito et al.'s (2013) Italian adaptation of the Recovery Experience Questionnaire (Sonnentag \& Fritz, 2007). A sample item is: "I distance myself from my work". Participants chose an alternative on a 5-point Likert scale, from 1 (I do not agree at all) to 5 (I fully agree). Cronbach's $\alpha$ in this study was .87 . 
Affectivity Positive and Negative Affect Schedule (PANAS; Watson et al., 1988) was used to assess subjective emotions, specifically through Terracciano et al.'s (2003) Italian version, consisting of two 5-item subscales for Positive Affect (PA) and Negative Affect (NA), respectively. Participants were asked to report on a Likert scale, from 1 (Very slightly or not at all) to 5 (Extremely), the extent to which they felt the emotional state indicated by each item, during last week. Sample items: "enthusiastic", "inspired" (PA) and "upset", "afraid" (NA). Cronbach's $\alpha$ in this study were .83 for PA and .83 for NA, respectively.

Perceived Health Subjectively perceived health was assessed through General Health Questionnaire (GHQ; Goldberg \& Williams, 1988), specifically through a shortened 6-item Italian version (Politi et al., 1994). Sample items are: "Did you feel under strain?", "Could you face your problems?". Subjects gave their answers using a 4-point scale, from 0 (Never) to 3 (More than usual). Cronbach's $\alpha$ in this study was .79.

\section{Analysis}

Preliminarily, confirmatory factor analysis (CFA) on all measures was conducted using Mplus 7 and the robust maximum likelihood estimation (MLR). This allowed to test whether the measures included in the study were distinct latent constructs, with items of each construct loading on the corresponding latent factor only. The latent factors were allowed to correlate with each other. The fit of this model was evaluated using several goodness-of-fit indices: $\chi^{2}$ to degree of freedom ratio $\left(\chi^{2} / \mathrm{df}\right)$, the Tucker-Lewis Index (TLI), the Comparative Fit Index (CFI), the Root Mean Square Error of Approximation (RMSEA), and the Standardized Root Mean Square Residual (SRMR). A $\chi^{2} / d f$ less than 3 indicates an acceptable fit, as does TLI and CFI values equal or higher than .90, RMSEA and SRMR with values of .08 or less (Hu \& Bentler, 1999; Kline, 2016). Furthermore, composite reliability (CR), average variance extracted (AVE), maximum shared variance (MSV) and average shared variance (ASV) of all the latent factors were computed, in order to assess the possible impact of common method bias and establish the discriminant validity of measures (Podsakoff et al., 2003). CR higher than .70, AVE of all the constructs higher than .50, and both ASV and MSV lower than AVE prove the convergent and discriminant validity of the measurement model (Farrell \& Rudd, 2009; Fornell \& Larcker, 1981).

Secondly, we attempted to identify profiles of our respondents based on their levels of workaholism, work engagement, and psychological detachment. In order to identify groups of employees with distinct workaholism, work engagement, and psychological detachment profiles, LPA was conducted, with the use of Mplus 7 and the MLR estimation, using $z$ - standardized mean scale scores of workaholism, work engagement, and psychological detachment scales as indicators. Models with two to ten profiles were estimated and compared with each other, following a stepwise approach to determine the number of latent profiles that best characterize the data and sample, starting with two profiles and successively adding profiles. The final model was chosen according to criteria of parsimony and interpretability. So, models with smaller AIC, BIC and sample-adjusted BIC (SABIC) were preferred over models with greater values in these indicators. Moreover, the $p$ values associated with Lo-Mendell-Rubin Likelihood Ratio Test and the Bootstrapped Likelihood Ratio Test were considered to reject models that did not fit the data better than a more parsimonious model. Finally, entropy was considered as an indicator of classification quality test: models with higher entropy value fit the data better (see Masyn, 2013; Spurk et al., 2020).

Following the analytical strategy usually applied to analyze differences in outcomes among different profiles (e.g., Feldt et al., 2013; Innanen et al., 2014), multivariate analysis of covariance (MANCOVA) was carried out in order to analyze differences among groups of employees featuring distinct profiles of workaholism, work engagement, and psychological detachment with regard to their average levels of outcomes (i.e., positive emotions, negative emotions, and perceived health).

\section{Results}

\section{Measurement Models, Descriptive and Associations among Variables}

As a first step, CFA was performed on the measures assessed in this study, with all the factors being allowed to correlate. The global fit statistics showed that the scales had a marginally acceptable construct validity, with some indices not reaching the standard of the acceptable model fit: $\chi^{2}(650)=$ $1709.831, \chi^{2} / d f=2.63, \mathrm{TLI}=.799, \mathrm{CFI}=.814$, RMSEA $=.069$, SRMR $=.073$. The examination of the modification indices suggested some correlation of item errors, all within the hypothesized factors (two items of workaholism, two items of GHQ, one of negative affectivity and one of positive affectivity). To allow the error terms of these items to correlate improved the model fit: $\chi^{2}(644)=1226.241, \chi^{2} /$ $d f=1.90, \mathrm{TLI}=.898, \mathrm{CFI}=.908$, RMSEA $=.051$, SRMR $=.071$. Thus, acceptable values were reached.

As can be seen in Table 1, AVE, MSV, and ASV values for all the latent factors fulfilled the requirements for convergent and discriminant validity. All the constructs achieved the recommended value for $\mathrm{CR}(>.70)$, the value of AVE exceeded the recommended value of .50 (Fornell \& Larcker, 1981), and both values of ASV and MSV were lower than the 
Table 1 Convergent and discriminant validity of the measurement model and means, standard deviations, internal consistencies (Cronbach's alpha) and intercorrelations among variables

\begin{tabular}{|c|c|c|c|c|c|c|c|c|c|c|c|c|c|c|c|c|c|}
\hline & & $\mathrm{CR}$ & AVE & MSV & ASV & $M$ & $S D$ & 1 & 2 & 3 & 4 & 5 & 6 & 7 & 8 & 9 & 10 \\
\hline 1 & Age & - & - & - & - & 42.55 & 12.68 & - & & & & & & & & & \\
\hline 2 & Gender $^{\mathrm{a}}$ & - & - & - & - & 1.44 & .50 & .05 & - & & & & & & & & \\
\hline 3 & Education $^{\mathrm{b}}$ & - & - & - & - & 3.36 & 1.07 & .08 & .22 & - & & & & & & & \\
\hline 4 & Tenure & - & - & - & - & 19.89 & 12.04 & .90 & -.08 & -.10 & - & & & & & & \\
\hline 5 & WA & .917 & .528 & .060 & .028 & 2.87 & .36 & -.01 & .00 & -.18 & .03 & $(.82)$ & & & & & \\
\hline 6 & WE & .918 & .560 & .520 & .171 & 3.96 & 1.12 & .08 & -.04 & .06 & .10 & .13 & $(.92)$ & & & & \\
\hline 7 & $\mathrm{PD}$ & .872 & .699 & .039 & .016 & 2.85 & 1.10 & -.01 & -.03 & .06 & -.02 & -.13 & -.09 & (.87) & & & \\
\hline 8 & $\mathrm{GH}$ & .867 & .521 & .244 & .093 & 2.18 & .60 & .13 & -.13 & .12 & .11 & -.28 & .24 & .16 & (.79) & & \\
\hline 9 & NA & .829 & .504 & .178 & .074 & 1.94 & .76 & -.15 & .11 & -.12 & -.12 & .23 & -.35 & -.11 & -.51 & (.83) & \\
\hline 10 & $\mathrm{PA}$ & .860 & .556 & .520 & .182 & 3.46 & .75 & -.06 & -.11 & .07 & -.03 & .15 & .63 & -.09 & .15 & -.19 & $(.83)$ \\
\hline
\end{tabular}

Note. $N=342 . \mathrm{CR}=$ Composite reliability; $\mathrm{AVE}=$ Average variance extracted; $\mathrm{MSV}=$ Maximum shared variance; $\mathrm{ASV}=\mathrm{Average}$ shared variance; $\mathrm{WA}=$ Workaholism; WE = Work Engagement; $\mathrm{PD}=$ Psychological Detachment; GH = General Health; NA = Negative Affect; PA = Positive Affect. Internal consistency estimates (Cronbach's alpha) are presented in parentheses in the diagonal. Numbers in bold $p<.05$

${ }^{\mathrm{a}} 1$ = female, 2 = male; ${ }^{\mathrm{b}}$ from $1=$ very low to $6=$ very high

corresponding values of AVE. Thus, the overall results for the measurement model indicated scale reliability and validity.

Table 1 presents also means, standard deviations, internal consistencies and correlations of all the study variables.

The intercorrelations showed, first, that workaholism was negatively correlated with psychological detachment, while work engagement was not significantly related to psychological detachment. Furthermore, workaholism negatively correlated with general health perceptions $(r=-.28)$ and positively with negative affectivity $(r=.23)$ and also with positive affectivity $(r=.15)$. Work engagement correlated positively with general health $(r=.24)$, negatively with negative affectivity $(r=-.35)$, and positively with positive affectivity $(r=.63)$. Lastly, psychological detachment correlated with two out of three outcomes, that is it was positively associated with general health $(r=.16)$ and negatively associated with negative affectivity $(r=-.11)$.

\section{Associations among the Latent Factors of Workaholism, Work Engagement and Psychological Detachment (LPA)}

The overall results emerging from the stepwise comparison of the latent profiles converged toward a 5-group solution. In fact, although the AIC, BIC and SABIC fit indices support the model with the highest number of profiles, the indicators of parsimony (VLMR and LRT Test) supported the models with two up to five profiles. Among these models, the 5-group solution showed the lowest fit indices and the best value of Entropy (.992), thus indicating that this solution provided a clear classification. Based on this evidence, the 5-group solution was retained (see Table 2 for the fit indices associated with the alternative LPA solutions). This solution is graphically displayed in Fig. 1 .

Profile 1 described $21.9 \%$ of our sample and showed the highest levels of engagement and of detachment but with the lowest levels of workaholism: they were labeled as "HighDetachment and Engaged". Profile 2 included the largest (33.0\%) part of our sample and can be labeled as "Heavy Work Investors", with moderately high levels of workaholism and work engagement and low levels of detachment. Profile 3 included $24.6 \%$ of employees who can be qualified as "MildDetachment and Disengaged", showing low levels of workaholism, the lowest levels of work engagement, and moderately high levels of detachment. Profile 4 consists of a proportion of employees (16.4\%) reporting moderately high levels of work engagement and detachment, and very low levels of workaholism: they were labeled "Mild-Detachment and Engaged". Finally, Profile 5 referred to a relatively small proportion of employees (4.1\%), presenting a "Pure Workaholics" pattern (i.e., the highest levels of workaholism and the lowest levels of work engagement and detachment). These results are partially in line with Hypothesis 1.

\section{Differences between Profiles on Associated Outcomes}

MANCOVA was used to test whether latent profile membership predicted outcomes of perceived health, negative affectivity and positive affectivity with age, gender, education and tenure entered as covariates. Only the independent variable (profile membership) yielded significant multivariate results: Pillai trace $=.220, F(12,331)=6.598, p<.0001$. When the outcome variables were considered separately, perceived health and negative affectivity reached statistical significance, but not positive affectivity, as can be seen in Table 3 . The 
Table 2 Fit indices for workaholism, work engagement and psychological detachment with different numbers of latent profiles in Latent Profile Analysis

\begin{tabular}{rllllllll}
\hline$k$ & LL & FP & AIC & BIC & SABIC & BLRT (p) & LMR (p) & Entropy \\
\hline 2 & -2321.772 & 10 & 4663.545 & 4701.893 & 4670.171 & $<.0001$ & $<.0001$ & .963 \\
3 & -2263.749 & 14 & 4555.498 & 4609.185 & 4564.774 & $<.0001$ & .0041 & .980 \\
4 & -2233.791 & 18 & 4503.582 & 4572.608 & 4515.508 & $<.0001$ & .0018 & .948 \\
5 & -1760.713 & 22 & 3565.426 & 3649.792 & 3580.003 & $<.0001$ & .0091 & .992 \\
6 & -2027.231 & 26 & 4106.461 & 4206.167 & 4123.689 & $<.0001$ & .3189 & .850 \\
7 & -1699.689 & 30 & 3459.379 & 3574.423 & 3479.256 & $<.0001$ & .0719 & .987 \\
8 & -1719.308 & 34 & 3506.615 & 3636.999 & 3529.143 & $<.0001$ & .4728 & .887 \\
9 & -1673.678 & 38 & 3423.356 & 3569.079 & 3448.534 & $<.0001$ & .1306 & .996 \\
10 & -1694.296 & 42 & 3472.593 & 3633.655 & 3500.422 & .0505 & .5728 & .906 \\
\hline
\end{tabular}

Note: $\mathrm{k}=$ number of latent profiles in the model; $\mathrm{LL}=$ model $\log$ likelihood value; $\mathrm{FP}=$ free parameters; $\mathrm{AIC}=$ Akaike Information Criterion; BIC $=$ Bayesian Information Criterion; SABIC $=$ Sample size-Adjusted BIC; $\operatorname{BLRT}(\mathrm{p})=\mathrm{p}$ Value for the bootstrapped likelihood ratio test. $\operatorname{LMR}(\mathrm{p})=p$ Value for the adjusted Lo-MendellRubin-test pairwise comparisons using the estimated marginal means and applying a Bonferroni adjustment to the confidence intervals indicated that the profiles Pure Workaholics, MildDetachment and Engaged, and Mild-Detachment and Disengaged scored significantly lower than the other two profiles in perceived health. Also, it showed that the profile Pure Workaholics had the highest score in negative affectivity, while the High-Detachment and Engaged had the lowest one. Overall, profiles with high levels of workaholism and low levels of work engagement and psychological detachment showed more negative perceived health and negative affectivity, while the profile High-Detachment and Engaged showed lower negative affectivity. On the other hand, positive affectivity scores do not appear to be different among profiles. Hence, Hypotheses 2 and 3 were partially supported.
Fig. 1 Final latent profile solution retained

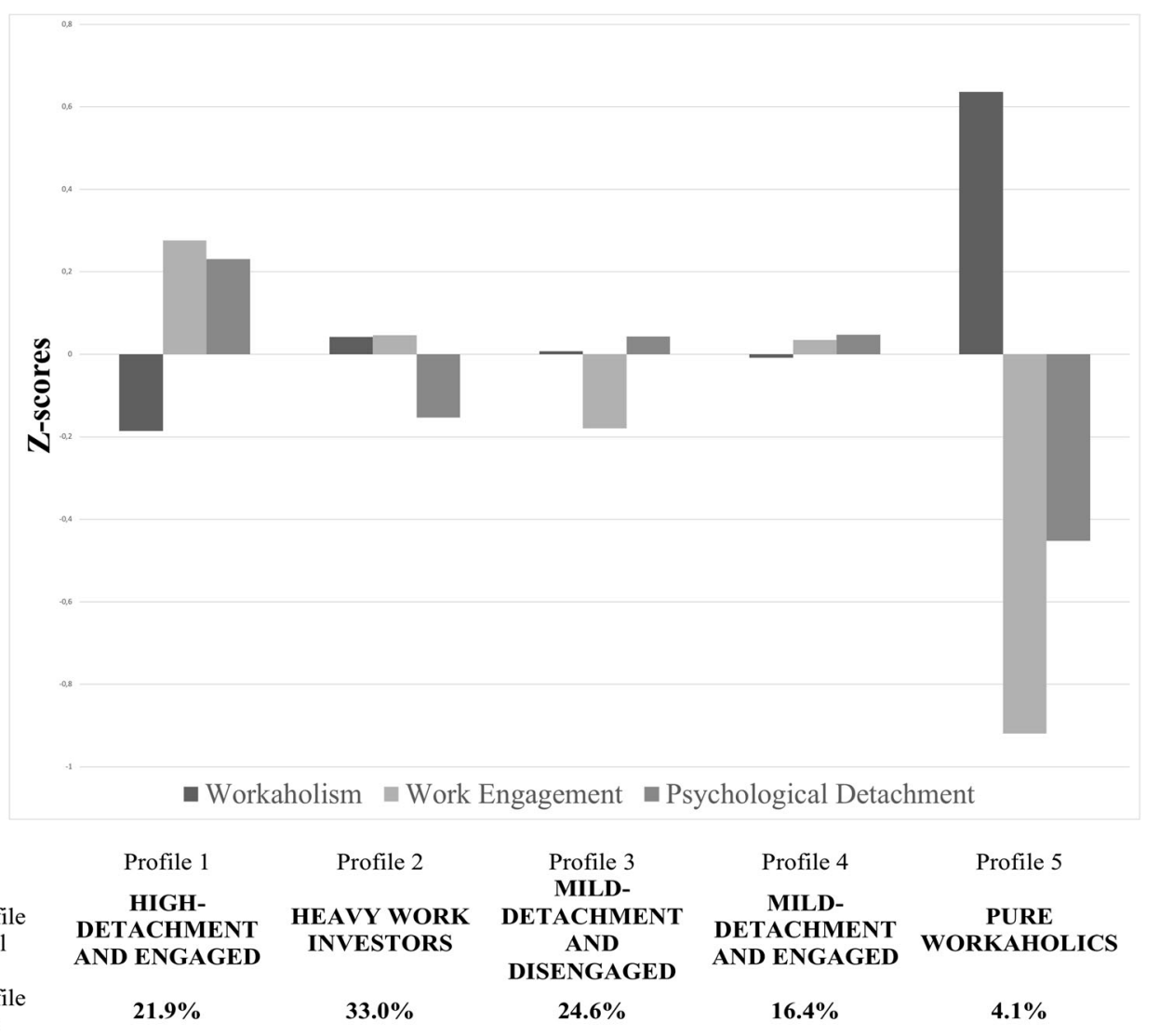




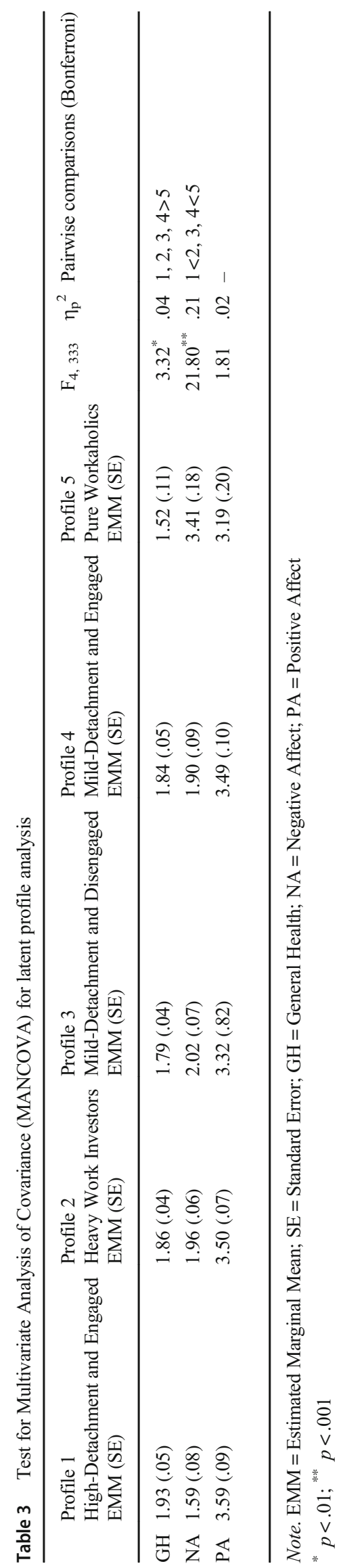

\section{Discussion}

The current study is the first one examining employee profiles with different levels of workaholism, work engagement, and psychological detachment, and their relationships with different well-being outcomes. By applying a person-centered perspective, five profiles were identified, based on the combination of workaholism, work engagement, and psychological detachment. This finding is in line with our initial expectation of identifying at least four employee profiles (Hypothesis 1).

The first profile (High-Detachment and Engaged) showed high level of work engagement and psychological detachment and low level of workaholism. Individuals of this profile were also the most engaged employees in the sample. The second profile (Heavy Work Investors) showed medium levels of both workaholism and work engagement, and low level of psychological detachment. Employees showing this pattern represented the largest group in the sample. The third profile (Mild-Detachment and Disengaged) showed low level of work engagement (and workaholism) and high level of psychological detachment and were the second largest group in the sample. The fourth profile (Mild-Detachment and Engaged) showed high level of work engagement and low level of psychological detachment (and workaholism). The fifth profile (Pure Workaholics) showed "the most extreme" pattern in our sample, with the highest level of workaholism and lowest levels of both work engagement and psychological detachment. Thus, not surprisingly, Pure Workaholics represented the smallest group in the sample.

In line with our expectations, we found that two profiles showed opposite patterns in the levels of work engagement and psychological detachment. As formulated in Hypothesis 1, Profile 2 consists of engaged workers (showing also workaholism) not being able to detach from work during off-job hours, while Profile 4 consists of engaged workers being able to detach from work. In addition, we identified a profile (Profile 3) of disengaged workers being able to detach from work. These findings confirm the mixed results reported in prior literature on the relationships between work engagement and psychological detachment from work (Kühnel et al., 2009; Shimazu et al., 2016; Shimazu et al., 2012; Siltaloppi et al., 2011; Sonnentag et al., 2010b). Engaged workers are likely to feel energized at work, but not all the engaged workers are able to detach from work-related thoughts and concerns outside of work, thus not being able to restore psychological resources.

Contrary to our expectations, the Heavy Work Investors profile (Profile 2) includes a group of employees, who scored moderately high in both workaholism and work engagement, with a low capacity of detachment from work. Heavy Work Investors also represented the largest group in the sample. Thus, we conclude that workaholism and work engagement can sometimes coexist within an individual, making 
impossible to distinguish the two types of HWI within some subjects. This is in line with the findings of Gillet et al. (2018), who identified a profile ("Engaged-Workaholic") scoring relatively high in both work engagement and workaholism. Future research should further examine work engagement and workaholism profiles using LPA to gain deeper insights into the profile of Heavy Work Investors. For instance, it would be interesting to investigate possible boundary conditions of the coexistence of workaholism and work engagement.

Furthermore, in line with Hypothesis 1, we found one profile (Pure Workaholics) with high (the highest) level of workaholism and at the same time low levels of work engagement and detachment. Although this group was the smallest in the sample, it represented the "traditional type" of workaholics. These employees do not show any specific enthusiasm for their job but are rather pushed to work and have difficulty to detach from work (e.g., Schaufeli et al., 2008; Schaufeli et al., 2009; van Wijhe et al., 2013).

Another finding did not meet our expectations. No profile emerged with low levels of psychological detachment, workaholism, and work engagement. All profiles had at least one prevailing high or low characteristic in their configuration.

Finally, our analysis revealed opposite patterns of psychological detachment and workaholism within each profile. Specifically, we found low workaholism but high detachment in Profile 1 and Profile 4, whereas we found high workaholism but low detachment in Profile 2 and Profile 5. This aligns our general assumption about the difficulty workaholics have in adequately alternating work and nonwork time and, furthermore, it confirms the findings from previous research on workaholism and psychological detachment (e.g., Sonnentag et al., 2008; Wendsche \& Lohmann-Haislah, 2017).

\section{Profiles and Differences in Outcomes}

The second part of our analysis tested the relationships between different profiles and different well-being outcomes, allowing us to delve into a comparison across profiles using a criterion-based differentiation.

In line with Hypothesis 2, we found that profiles with high level of workaholism and low level of work engagement are associated with higher negative affectivity, lower positive affectivity, and poorer general health than profiles with low level of workaholism and high level of work engagement. In line with Hypothesis 3, we found that profiles with high level of psychological detachment are associated with higher positive affectivity, better general health, and lower negative affectivity than profiles with low level of psychological detachment.

The first profile (High-Detachment and Engaged) was associated with the highest positive outcomes. Specifically, employees of Profile 1 reported better general health status, higher positive affectivity and lower negative affectivity than the other four profiles. Thus, this finding supports Hypotheses 2 and 3. In Hypothesis 2, we predicted more positive outcomes and less negative outcomes for profiles with low levels of workaholism and high levels of work engagement, and in Hypothesis 3 we made the same prediction on outcomes for profiles with high levels of psychological detachment than others. We conclude that employees can experience the highest well-being when they are simultaneously engaged in their work and able to mentally disconnect from work-related thoughts during nonwork hours.

The second profile (Heavy Work Investors) was associated with high good general health status, high positive affectivity, high negative affectivity. In line with Hypothesis 3, this might be due to the lack of the ability to psychologically detach from work (Sonnentag \& Fritz, 2007, 2015), which represented the main difference between this second profile and the fourth profile, Mild-Detachment and Engaged. Mentally detaching from work would further protect this group of workers, as it can be supposed for the fourth profile (see below).

The third profile (Mild-Detachment and Disengaged) was associated with relatively poor general health status, high positive affectivity and high negative affectivity. The levels of the three outcomes are therefore similar but less extreme than those reported for Profile 5 (Pure Workaholics). The disengagement of employees within this profile might be the explanation for the poor well-being outcomes. Even though employees with Profile 3 were to a certain extent able to detach from work, they lacked the vigor and dedication that could help them alleviate the negative effect of their work investment (Schaufeli et al., 2006b; Schaufeli et al., 2009; van Wijhe et al., 2013).

The fourth profile (Mild-Detachment and Engaged) is associated with good general health status, high positive affectivity and high negative affectivity, although, to a lower extent than Profile 2 outcomes. Employees in this group reported better general health status, and higher positive affectivity than employees with Profile 3. This result might be explained by the resource restoring effect of psychological detachment from work. As posited by SDM, detaching from work helps relieve the stress accumulated during the workday by restoring the resources after a work-related effort (Sonnentag \& Fritz, 2007, 2015). Thus, this finding gives support to Hypothesis 3.

The fifth profile (Pure Workaholics) is associated with the poorest general health status, the lowest positive affectivity, and the highest negative affectivity. The associations between Profile 5 and the three outcome variables seem to have the opposite pattern compared to Profile 1 (High-Detachment and Engaged). These findings give further support to Hypotheses 2 and 3, and are in line with prior literature on the association between a workaholic approach to work and poor well-being outcomes (e.g., Clark et al., 2016; van Beek et al., 2014; van Wijhe et al., 2013). 
Our work adds to the existing examination of heavy work investor characteristics by proposing psychological detachment as an additional dimension that can differentiate between HWI profiles. Previous studies examined the two types of HWI (workaholism and work engagement), either in isolation or in combination with other constructs (Gillet et al., 2018; Mäkikangas et al., 2013). We focused on a specific recovery experience, namely psychological detachment from work during off-job hours (Sonnentag \& Fritz, 2007), and we investigated it in combination with the two types of HWI. The results indicate that psychological detachment can be beneficial for certain types of heavy work investors. Overall, profiles with high and medium detachment have been associated with better well-being outcomes than low detachment profiles. More specifically, profiles with high work engagement and high detachment were associated with the highest well-being outcomes. Yet, an interesting finding is that employees with high engagement and low detachment (Heavy work investors) reported almost equally high well-being outcomes as profiles with high detachment. Thus, we conclude that being spontaneously enthusiast about one's work (i.e., engagement) might play even a more important role in stress prevention, than the ability of psychological detachment. This study extends the findings of Gillet et al. (2018) stating that workaholism "eliminates the positive effects of work engagement", even if "high levels of work engagement could help buffer employees against the negative effects of workaholism" (p. 68). By including psychological detachment as a third variable, we provide more in-depth insights into the combined effect of workaholism and work engagement.

\section{Limitations and Future Research}

While our study has several strengths, it is also subject to some limitations. First, data were collected through self-report questionnaires. Although the CFA and convergent/discriminant validity test showed that common method bias was not a threat in the study (Podsakoff et al., 2003), future research should consider other methods for measuring HWI variables.

Second, a cross-sectional design was used for this study. Consequently, although we hypothesized a particular causal order of the variables, other causal relations might be possible as well. Another limitation of a cross-sectional design is that variables such as workaholism, work engagement, and psychological detachment and the corresponding phenomena need to be interpreted in a static condition, without taking into account the time element. As stated in recent reviews on between- and within- subject research, whether time is addressed in a study can dramatically change the output, interpretation, and meaning of research (McCormick et al., 2020). Previous studies have examined workaholism, work engagement, and psychological detachment in isolation using a longitudinal design (e.g., Bakker, 2014; Binnewies \& Fetzer,
2010; McMillan et al., 2001). We argue that future research should simultaneously investigate the three variables at different points in time, in particular by adopting a diary study design.

Third, we did not take into account the working conditions that may influence workaholism, work engagement and psychological detachment. For example, prior research has shown that these variables are differently related to the different job resources and job stressors (e.g., Clark et al., 2016; Christian et al., 2011; Steed et al., 2019). Thus, future research should examine whether and how different working conditions affect employee profiles of workaholism, work engagement and psychological detachment from work.

Another fruitful avenue for future research would be to investigate the relation between workaholism and work engagement by setting a deeper focus on the underlying dimensions of each constructs. This would allow researchers to refine their comprehension of workaholism and work engagement with greater precision and tackle the ambiguity still present at the construct level (as suggested by one of the reviewers of an early version of this paper). Also, a finer understanding of the possible coexistence workaholism and work engagement would give more opportunities to identify "who are" the highly engaged and highly workaholic employees, and to develop organizational strategy on preventing the negative impact of workaholism and fostering the positive impact of work engagement on employee well-being.

\section{Practical Implications}

In the organizational context, HWI behaviors might easily be praised and rewarded as a desirable productive behavior without fully understanding their underlying nature (workaholism vs. work engagement). However, it is important to distinguish between a workaholic and an engaged approach to work to protect and foster employees' well-being (e.g., Kim, 2019; van Wijhe et al., 2011). Disentangling the relationship between HWI and unfavorable health-related outcomes would allow organizations to assess the severity of such behaviors and, to encourage employees to have a healthy balance between work, home, and leisure activities (Aziz \& Moyer, 2018; Nerstad et al., 2019). Our findings indicate that employees might be highly workaholic and highly engaged at the same time, which requires special attention from organizations. We recommend to apply a promotion strategy of fostering both engagement and detachment ability, instead of a prevention strategy of buffering workaholism. The results suggest that the capacity of psychological detachment seems to contribute to mitigating the detrimental effects of HWI, although this effect to be stronger when coupled with high work engagement. Thus, in line with previous research (e.g., Sonnentag \& Fritz, 2015; Sonnentag et al., 2013), we argue that psychological detachment can be certainly a resource for 
heavy work investors to prevent work strain and subsequent health impairments. However, it is also important to note that highly engaged employees seem to be "already protected" from experiencing negative well-being outcomes. By contrast, highly workaholic employees seem to be more at risk of experiencing negative outcomes of HWI, due also to a lack of detachment capacity.

Based on our findings, we suggest organizations to introduce organizational policies on fostering employee engagement to mitigate the potential negative consequences of HWI. This strategy can be more effective than other strategies of simply identifying and discouraging an unhealthy approach to work (workaholism) or fostering psychological detachment. Accordingly, managers and HR professionals should apply specific measures and interventions to increase engagement among employees to sustain their well-being. In addition, managers and HR professionals can also support individuals' capacity to detach from work during off-job hours, as this would further support and maximize the positive outcome in employee well-being.

Acknowledgements The authors would like to thank Dorottya Varga for careful English proofreading of the manuscript.

Data Availability Statement The data that support the findings of this study are available from the corresponding author upon reasonable request.

Funding Open access funding provided by Università degli Studi di Palermo within the CRUI-CARE Agreement.

\section{Declarations}

Declaration of Interest Statement On behalf of all authors, the corresponding author states that there is no conflict of interest.

Open Access This article is licensed under a Creative Commons Attribution 4.0 International License, which permits use, sharing, adaptation, distribution and reproduction in any medium or format, as long as you give appropriate credit to the original author(s) and the source, provide a link to the Creative Commons licence, and indicate if changes were made. The images or other third party material in this article are included in the article's Creative Commons licence, unless indicated otherwise in a credit line to the material. If material is not included in the article's Creative Commons licence and your intended use is not permitted by statutory regulation or exceeds the permitted use, you will need to obtain permission directly from the copyright holder. To view a copy of this licence, visit http://creativecommons.org/licenses/by/4.0/.

\section{References}

Andreassen, C. S. (2014). Workaholism: An overview and current status of the research. Journal of Behavioral Addictions, 3(1), 1-11. https://doi.org/10.1556/JBA.2.2013.017.
Aziz, S., \& Moyer, F. (2018). Workaholism and occupational health: A translational review. Journal of Applied Biobehavioral Research, 23, e12144. https://doi.org/10.1111/jabr.12144.

Babic, A., Stinglhamber, F., Barbier, M., \& Hansez, I. (2019). Work environment and work-to-family conflict: Examining the mediating role of heavy work investment. Journal of Management \& Organization. Advance online publication., 1-24. https://doi.org/ 10.1017/jmo.2019.40.

Bakker, A. B. (2014). Daily fluctuations in work engagement: An overview and current directions. European Psychologist, 19, 227-236. https://doi.org/10.1027/1016-9040/a000160.

Balducci, C., Avanzi, L., Consiglio, C., Fraccaroli, F., \& Schaufeli, W. (2015). A cross-national study on the psychometric quality of the Italian version of the Dutch work addiction scale (DUWAS). European Journal of Psychological Assessment, 33(6), 422-428. https://doi.org/10.1027/1015-5759/a000300.

Balducci, C., Fraccaroli, F., \& Schaufeli, W. B. (2010). Psychometric properties of the Italian version of the Utrecht work engagement scale (UWES-9): A cross-cultural analysis. European Journal of Psychological Assessment, 26(2), 143-149. https://doi.org/10. 1027/1015-5759/a000020.

Bakker, A. B., \& Demerouti, E. (2017). Job demands-resources theory: Taking stock and looking forward. Journal of Occupational Health Psychology, 22, 273-285. https://doi.org/10.1037/ocp0000056.

Bakker, A. B., Demerouti, E., Oerlemans, W., \& Sonnentag, S. (2013). Workaholism and daily recovery: A day reconstruction study of leisure activities. Journal of Organizational Behavior, 34(1), 87107. https://doi.org/10.1002/job.1796.

Bennett, A. A., Bakker, A. B., \& Field, J. G. (2018). Recovery from work-related effort: A meta-analysis. Journal of Organizational Behavior, 39(3), 262-275. https://doi.org/10.1002/job.2217.

Binnewies, C., \& Fetzer, B. (2010). Affective state and affect regulation as antecedents of dynamic work engagement. In S. L. Albrecht (Ed.), Handbook of employee engagement: Perspectives, issues, research and practice (pp. 245-252). Elgar.

Clark, M. A., Michel, J. S., Stevens, G. W., Howell, J. W., \& Scruggs, R. S. (2014). Workaholism, work engagement and work-home outcomes: Exploring the mediating role of positive and negative emotions. Stress and Health, 30(4), 287-300. https://doi.org/10.1002/ smi.2511.

Clark, M. A., Michel, J. S., Zhdanova, L., Pui, S. Y., \& Baltes, B. B. (2016). All work and no play? A meta-analytic examination of the correlates and outcomes of workaholism. Journal of Management, 42(7), 1836-1873. https://doi.org/10.1177/0149206314522301.

Christian, M. S., Garza, A. S., \& Slaughter, J. E. (2011). Work engagement: A quantitative review and test of its relations with task and contextual performance. Personnel Psychology, 64(1), 89-136.

del Líbano, M. (2011). A journey into the heart of workaholism: Empirical findings from several multi-sample studies (doctoral dissertation). Universitat Jaume I.

del Líbano, M., Llorens, S., Salanova, M., \& Schaufeli, W. B. (2012). About the dark and bright sides of self-efficacy: Workaholism and work engagement. The Spanish Journal of Psychology, 15(2), 688701. https://doi.org/10.5209/rev_SJOP.2012.v15.n2.38883.

Di Stefano, G., \& Gaudiino, M. (2018). Differential effects of workaholism and work engagement on the interference between life and work domains. Europe's Journal of Psychology, 14(4), 863-879. https:// doi.org/10.5964/ejop.v14i4.1626.

Di Stefano, G., \& Gaudiino, M. (2019). Workaholism and work engagement: How are they similar? How are they different? A systematic review and meta-analysis. European Journal of Work and Organizational Psychology, 28(3), 329-347. https://doi.org/10. 1080/1359432X.2019.1590337.

Etzion, D., Eden, D., \& Lapidot, Y. (1998). Relief from job stressors and burnout: Reserve service as a respite. Journal of Applied 
Psychology, 83(4), 577-585. https://doi.org/10.1037/0021-9010.83. 4.577.

Farrell, A. M., \& Rudd, J. M. (2009). Factor analysis and discriminant validity: A brief review of some practical issues. ANZMAC 2009 conference proceedings.

Fornell, C., \& Larcker, D. F. (1981). Evaluating structural equation models with unobservable variables and measurement error. Journal of Marketing Research, 18(1), 39-50. https://doi.org/10. 2307/3151312.

Fassel, D. (1990). Working ourselves to death: The high cost of workaholism, the rewards of recovery. Harper \& Collins.

Feldt, T., Huhtala, M., Kinnunen, U., Hyvönen, K., Mäkikangas, A., \& Sonnentag, S. (2013). Long-term patterns of effort-reward imbalance and over-commitment: Investigating occupational well-being and recovery experiences as outcomes. Work \& Stress, 27(1), 64 87. https://doi.org/10.1080/02678373.2013.765670.

Fritz, C., \& Sonnentag, S. (2005). Recovery, health, and job performance. Effects of weekend experiences Journal of Occupational Health Psychology, 10(3), 187-199. https://doi.org/10.1037/1076-8998. 10.3.187.

Fritz, C., \& Sonnentag, S. (2006). Recovery, well-being, and performance-related outcomes: The role of workload and vacation experiences. Journal of Applied Psychology, 91(4), 936-945. https://doi.org/10.1037/0021-9010.91.4.936.

Gillet, N., Morin, A. J. S., Sandrin, E., \& Houle, S. A. (2018). Investigating the combined effects of workaholism and work engagement: A substantive-methodological synergy of variablecentered and person-centered methodologies. Journal of Vocational Behavior, 109, 54-77. https://doi.org/10.1016/j.jvb. 2018.09.006.

Goldberg, D., \& Williams, P. (1988). A user's guide to the general health questionnaire. Windsor: NferNelson.

Gorgievski, M. J., Bakker, A. B., \& Schaufeli, W. B. (2010). Work engagement and workaholism: Comparing the self-employed and salaried employees. Journal of Positive Psychology, 5(1), 83-96. https://doi.org/10.1080/17439760903509606.

Guidetti, G., Viotti, S., \& Converso, D. (2020). The interplay between work engagement, workaholism, emotional exhaustion and job satisfaction in academics: A person-centred approach to the study of occupational well-being and its relations with job hindrances and job challenges in an Italian university. Higher Education Quarterly, 74(3), 224-239. https://doi.org/10.1111/hequ.12239.

Hakanen, J., Rodríguez-Sánchez, A. M., \& Perhoniemi, R. (2012). Too good to be true? Similarities and differences between engagement and workaholism among Finnish judges. Ciencia \& Trabajo, 14, $72-80$.

Hu, L. T., \& and Bentler, P. M. (1999). Cutoff criteria for fit indexes in covariance structure analysis: Conventional criteria versus new alternatives. Structural Equation Modeling: A Multidisciplinary Journal, 6(1), 1-55. doi:https://doi.org/10.1080/ 10705519909540118

Hu, Q., Schaufeli, W., Taris, T. W., Hessen, D. J., Hakanen, J., Salanova, M., \& Shimazu, A. (2014). "East is east and west is west and never the twain shall meet": Work engagement and workaholism across eastern and Western cultures. Procedia: Social and Behavioral Sciences, 1, 6-24.

Innanen, H., Tolvanen, A., \& Salmela-Aro, K. (2014). Burnout, work engagement and workaholism among highly educated employees: Profiles, antecedents and outcomes. Burnout Research, 1(1), 38-49. https://doi.org/10.1016/j.burn.2014.04.001.

Kim, S. (2019). Workaholism, motivation, and addiction in the workplace: A critical review and implications for HRD. Human Resource Development Review, 18(3), 325-348.

Kline, R. B. (2016). Principles and practice of structural equation modeling (4th ed.). Guilford Press.
Kühnel, J., Sonnentag, S., \& Westman, M. (2009). Does work engagement increase after a short respite? The role of job involvement as a double-edged sword. Journal of Occupational and Organizational Psychology, 82(3), 575-594. https://doi.org/10.1348/ 096317908 X349362.

Mäkikangas, A., Schaufeli, W., Tolvanen, A., \& Feldt, T. (2013). Engaged managers are not workaholics: Evidence from a longitudinal person-centered analysis. Revista de Psicología del Trabajo y de las Organizaciones, 29, 135-143.

Masyn, K. E. (2013). Latent class analysis and finite mixture modelling. In T. D. Little (Ed.), The Oxford handbook of quantitative methods in psychology (pp. 551-611). Oxford University Press.

McMillan, L. H., O'Driscoll, M. P., Marsh, N. V., \& Brady, E. C. (2001). Understanding workaholism: Data synthesis, theoretical critique, and future design strategies. International Journal of Stress Management, 8(2), 69-91. https://doi.org/10.1023/A: 1009573129142.

McCormick, B. W., Reeves, C. J., Downes, P. E., Li, N., \& Ilies, R. (2020). Scientific contributions of within-person research in management: Making the juice worth the squeeze. Journal of Management, 46(2), 321-350. https://doi.org/10.1177/ 0149206318788435.

Montgomery, A. J., Peeters, M. C. W., Schaufeli, W. B., \& Ouden, M. D. (2003). Work-home interference among newspaper managers: Its relationship with burnout and engagement. Anxiety, Stress, and Coping, 16(2), 195-211. https://doi.org/10.1080/ 1061580021000030535.

Moyle, P. (1995). The role of negative affectivity in the stress process: Tests of alternative models. Journal of Organizational Behavior, 16(S1), 647-668. https://doi.org/10.1002/job.4030160705.

Nerstad, C. G. L., Wong, S. I., \& Richardsen, A. M. (2019). Can engagement go awry and lead to burnout? The moderating role of the perceived motivational climate. International Journal of Environmental Research and Public Health, 16(11), 1979. https:// doi.org/10.3390/ijerph16111979.

Ng, T. W., Sorensen, K. L., \& Feldman, D. C. (2007). Dimensions, antecedents, and consequences of workaholism: A conceptual integration and extension. Journal of Organizational Behavior, 28(1), 111-136. https://doi.org/10.1002/job.424.

Podsakoff, P. M., MacKenzie, S. B., Lee, J.-Y., \& Podsakoff, N. P. (2003). Common method biases in behavioral research: A critical review of the literature and recommended remedies. Journal of Applied Psychology, 88(5), 879-903. https://doi.org/10.1037/ 0021-9010.88.5.879.

Politi, P. L., Piccinelli, M., \& Wilkinson, G. (1994). Reliability, validity and factor structure of the 12-item general health questionnaire among young males in Italy. Acta Psychiatrica Scandinavica, 90(6), 432-437. https://doi.org/10.1111/j.1600-0447.1994. tb01620.x.

Porter, G. (1996). Organizational impact of workaholism: Suggestions for researching the negative outcomes of excessive work. Journal of Occupational Health Psychology, 1(1), 70-84. https://doi.org/10. 1037/1076-8998.1.1.70.

Schaufeli, W. B., Bakker, A. B., \& Salanova, M. (2006a). The measurement of work engagement with a short questionnaire: A crossnational study. Educational and Psychological Measurement, 66(4), 701-716. https://doi.org/10.1177/0013164405282471.

Schaufeli, W. B., \& Salanova, M. (2011). Work engagement: On how to better catch a slippery concept. European Journal of Work and Organizational Psychology, 20(1), 39-46. https://doi.org/10.1080/ 1359432 X.2010.515981.

Schaufeli, W. B., Salanova, M., González-Romá, V., \& Bakker, A. B. (2002). The measurement of engagement and burnout: A two sample confirmatory factor analytic approach. Journal of Happiness Studies, 3(1), 71-92. https://doi.org/10.1023/a:1015630930326. 
Schaufeli, W. B., Shimazu, A., Hakanen, J., Salanova, M., \& De Witte, H. (2019). An ultra-short measure for work engagement: The UWES-3 validation across five countries. European Journal of Psychological Assessment, 35(4), 577-591. https://doi.org/10. 1027/1015-5759/a000430.

Schaufeli, W. B., Shimazu, A., \& Taris, T. W. (2009). Being driven to work excessively hard: The evaluation of a two-factor measure of workaholism in the Netherlands and Japan. Cross-Cultural Research, 43(4), 320-348. https://doi.org/10.1177/ 1069397109337239.

Schaufeli, W. B., Taris, T. W., \& Bakker, A. B. (2006b). Dr. Jekyll or Mr. Hyde?: On the differences between work engagement and workaholism. In R. J. Burke (Ed.), Research companion to working time and work addiction (pp. 193-217). Elgar.

Schaufeli, W. B., Taris, T. W., \& van Rhenen, W. (2008). Workaholism, burnout, and work engagement: Three of a kind or three different kinds of employee well-being? Applied Psychology, 57(2), 173203. https://doi.org/10.4337/9781847202833.00018.

Scott, K. S., Moore, K. S., \& Miceli, M. P. (1997). An exploration of the meaning and consequences of workaholism. Human Relations, 50(3), 287-314. https://doi.org/10.1177/001872679705000304.

Shimazu, A., De Jonge, J., Kubota, K., \& Kawakami, N. (2014). Psychological detachment from work during off-job time: Predictive role of work and non-work factors in Japanese employees. Industrial Health, 52(2), 141-146. https://doi.org/10. 2486/indhealth.2013-0210.

Shimazu, A., Matsudaira, K., De Jonge, J., Tosaka, N., Watanabe, K., \& Takahashi, M. (2016). Psychological detachment from work during non-work time: Linear or curvilinear relations with mental health and work engagement? Industrial Health, 54(3), 282-292. https:// doi.org/10.2486/indhealth.2015-0097.

Shimazu, A., \& Schaufeli, W. B. (2009). Is workaholism good or bad for employee wellbeing? The distinctiveness of workaholism and work engagement among Japanese employees. Industrial Health, 47(5), 495-502. https://doi.org/10.2486/indhealth.47.495.

Shimazu, A., Sonnentag, S., Kubota, K., \& Kawakami, N. (2012). Validation of the Japanese version of the recovery experience questionnaire. Journal of Occupational Health, 54, 54(3), 196, 196-205, 205. https://doi.org/10.1539/joh.11-0220-oa.

Shimazu, A., Schaufeli, W. B., Kamiyama, K., \& Kawakami, N. (2015). Workaholism vs. work engagement: The two different predictors of future well-being and performance. International Journal of Behavioral Medicine, 22, 18-23. https://doi.org/10.1007/s12529014-9410-x.

Siltaloppi, M., Kinnunen, U., \& Feldt, T. (2009). Recovery experiences as moderators between psychosocial work characteristics and occupational well-being. Work and Stress, 23(4), 330-348. https://doi. org/10.1080/02678370903415572.

Siltaloppi, M., Kinnunen, U., Feldt, T., \& Tolvanen, A. (2011). Identifying patterns of recovery experiences and their links to psychological outcomes across one year. International Archives of Occupational and Environmental Health, 84(8), 877-888. https:// doi.org/10.1016/j.burn.2014.04.001.

Snir, R., \& Harpaz, I. (2012). Beyond workaholism: Towards a general model of heavy work investment. Human Resource Management Review, 22(3), 232-243. https://doi.org/10.1016/j.hrmr.2011.11. 011.

Sonnentag, S. (2012). Psychological detachment from work during leisure time: The benefits of mentally disengaging from work. Current Directions in Psychological Science, 21(2), 114-118. https://doi. org/10.1177/0963721411434979.

Sonnentag, S., \& Bayer, U.-V. (2005). Switching off mentally: Predictors and consequences of psychological detachment from work during off-job time. Journal of Occupational Health Psychology, 10(4), 393-414. https://doi.org/10.1037/1076-8998.10.4.393.
Sonnentag, S., Binnewies, C., \& Mojza, E. J. (2010a). Staying well and engaged when demands are high: The role of psychological detachment. Journal of Applied Psychology, 95(5), 965-976. https://doi. org/10.1037/a0020032.

Sonnentag, S., \& Fritz, C. (2007). The recovery experience questionnaire: Development and validation of a measure for assessing recuperation and unwinding from work. Journal of Occupational Health Psychology, 12(3), 204-221. https://doi.org/10.1037/1076-8998. 12.3.204.

Sonnentag, S., \& Fritz, C. (2015). Recovery from job stress: The stressordetachment model as an integrative framework. Journal of Organizational Behavior, 36(S1), S72-S103. https://doi.org/10. 1002/job.1924.

Sonnentag, S., \& Kruel, U. (2006). Psychological detachment from work during off-job time: The role of job stressors, job involvement, and recovery-related self-efficacy. European Journal of Work and Organizational Psychology, 15(2), 197-217. https://doi.org/10. 1080/13594320500513939.

Sonnentag, S., Kuttler, I., \& Fritz, C. (2010b). Job stressors, emotional exhaustion, and need for recovery: A multi-source study on the benefits of psychological detachment. Journal of Vocational Behavior, 76(3), 355-365. https://doi.org/10.1016/j.jvb.2009.06. 005.

Sonnentag, S., Mojza, E. J., Binnewies, C., \& Scholl, A. (2008). Being engaged at work and detached at home: A week-level study on work engagement, psychological detachment, and affect. Work \& Stress, 22(3), 257-276. https://doi.org/10.1080/02678370802379440.

Sonnentag, S., Unger, D., \& Nägel, I. J. (2013). Workplace conflict and employee well-being: The moderating role of detachment from work during off-job time. International Journal of Conflict Management, 24(2), 166-183. https://doi.org/10.1108/ 10444061311316780.

Spector, P. E., Zapf, D., Chen, P. Y., \& Frese, M. (2000). Why negative affectivity should not be controlled in job stress research: Don't throw out the baby with the bath water. Journal of Organizational Behavior, 21(1), 79-95. https://doi.org/10.1002/(sici)10991379(200002)21:1<79::aid-job964>3.0.co;2-g.

Spence, J. T., \& Robbins, A. S. (1992). Workaholism: Definition, measurement, and preliminary results. Journal of Personality Assessment, 58(1), 160-178. https://doi.org/10.1207/ s15327752jpa5801_15.

Spurk, D., Hirschi, A., Wang, M., Valero, D., \& Kauffeld, S. (2020). Latent profile analysis: A review and "how to" guide of its application within vocational behavior research. Journal of Vocational Behavior, 103445, 103445. https://doi.org/10.1016/j.jvb.2020. 103445.

Steed, L. B., Swider, B. W., Keem, S., \& Liu, J. T. (2019). Leaving work at Work: A Meta-Analysis on Employee Recovery From Work. Journal of Management. https://doi.org/10.1177/ 0149206319864153.

Taris, T. W., Schaufeli, W. B, \& Verhoeven, L. C. (2005). Workaholism in the Netherlands: Measurement and implications for job strain and work-nonwork conflict. Applied Psychology: An International Review, 54(1), 37-60. doi:https://doi.org/10.1111/j.1464-0597. 2005.00195.x

Taris, T. W., Schaufeli, W. B., \& Shimazu, A. (2010). The push and pull of work: The difference between workaholism and work engagement. In A. B. Bakker \& M. P. Leiter (Eds.), Work engagement: A handbook of essential theory and research (pp. 39-53). Psychology Press.

Taris, T. W., Van Beek, I., \& Schaufeli, W. B. (2015). The beauty versus the beast: On the motives of engaged and workaholic employees. In I. Harpaz \& R. Snir (Eds.), Heavy work investment: Its nature, sources, outcomes, and future directions (pp. 121-138). Taylor \& Francis. 
ten Brummelhuis, L. L., \& Bakker, A. B. (2012). Staying engaged during the week: The effect of off-job activities on next day work engagement. Journal of Occupational Health Psychology, 17(4), 445-455. https://doi.org/10.1037/a0029213.

Terracciano, A., McCrae, R. R., \& Costa Jr., P. T. (2003). Factorial and construct validity of the Italian positive and negative affect schedule (PANAS). European Journal of Psychological Assessment, 19(2), 131-141. https://doi.org/10.1027/1015-5759.19.2.131.

Van Beek, I., Taris, T. W., \& Schaufeli, W. B. (2011). Workaholic and work engaged employees: Dead ringers or worlds apart? Journal of Occupational Health Psychology, 16(4), 468-482. https://doi.org/ 10.1037/a0024392.

van Beek, I. W., Taris, T. B., Schaufeli, W., \& Brenninkmeijer, V. (2014). Heavy work investment: Its motivational make-up and outcomes. Journal of Managerial Psychology, 29(1), 46-62. https://doi.org/10. 1108/jmp-06-2013-0166.

van Wijhe, C., Peeters, M., Schaufeli, W., \& Ouweneel, E. (2013). Rise and shine: Recovery experiences of workaholic and nonworkaholic employees. European Journal of Work and Organizational Psychology, 22(4), 476-489. https://doi.org/10.1080/1359432X. 2012.663527 van Wijhe, C., Peeters, M., Schaufeli, W., \& van den Hout, M. (2011). Understanding workaholism and work engagement: The role of mood and stop rules. Career Development International, 16(3), 254-270. https://doi.org/10.1108/13620431111140156.

Watson, D., Clark, L. A., \& Tellegen, A. (1988). Development and validation of brief measures of positive and negative affect: The PANAS scales. Journal of Personality and Social Psychology, 54(6), 1063-1070. https://doi.org/10.1037/0022-3514.54.6.1063.

Wendsche, J., \& Lohmann-Haislah, A. (2017). A meta-analysis on antecedents and outcomes of detachment from work. Frontiers in Psychology, 7. https://doi.org/10.3389/fpsyg.2016.02072.

Zito, M., Molino, M., \& Sonnentag, S. (2013). Adattamento italiano del Recovery Experience Questionnaire. [Italian adaptation of Recovery Experience Questionnaire] Poster - Giornate Nazionali di Psicologia Positiva VI Edizione "Promuovere Risorse nel Cambiamento", Milano, 22-23 febbraio 2013.

Publisher's note Springer Nature remains neutral with regard to jurisdictional claims in published maps and institutional affiliations. 